\title{
Flap bipedicular no tratamento de lesão cutânea traumática em membro torácico de gato: relato de caso*
}

\section{Bipedicular flap in the treatment of traumatic skin injury in cat thoracic member: case report}

\author{
Matheus Henrique Cargnin Borella, ${ }^{* *}$ Rafael Ricardo Huppes, ${ }^{* *}$ Cristhian Rene Vargas Estrada, ${ }^{* * *}$ Jorge Luiz Costa Castro, ${ }^{* * *}$ \\ Andrigo Barboza De Nardi, ${ }^{* * *}$ Joziane Morais Pazzini, ${ }^{* * * *}$ Rodrigo Jesus Paolozzi, ${ }^{* *}$
}

\begin{abstract}
Resumo
O objetivo do presente estudo é relatar a construção de um retalho direto de bolsa bipediculada com fixação apendicular à região torácica para o tratamento de lesões extensas no membro torácico direito de um gato. Foi tratado no Hospital Veterinário Unicesumar Maringá - Paraná, um felino de 1 ano de idade, apresentando lesão no membro torácico, após história de briga com outro animal da mesma espécie. Ao exame físico, apresentava fístula e edema no membro torácico direito. O paciente foi anestesiado e foi realizado o desbridamento das áreas desvitalizadas. Como terapia inicial, a lesão foi tratada como ferida aberta, até a formação de tecido de granulação, para posterior correção do defeito empregando retalho bipediculado em bolsa direta, com fixação temporária do membro à parede torácica. Após duas semanas, o membro foi desimplantado e os pontos foram removidos 21 dias após a aplicação do retalho. O uso do retalho permitiu completa cicatrização da ferida, sem ocorrência de hematomas, necrose ou deiscência de sutura. Conclui-se que a utilização do retalho bipedicular é aplicável ao tratamento de feridas traumáticas em membro torácico de felinos.
\end{abstract}

Palavras-chave: Felinos, ferida cutânea, retalho.

\begin{abstract}
The aim of the present study is to report the construction of a direct bipedicled pouch flap with appendicular fixation to the thoracic region for the treatment of extensive lesions in the right thoracic limb of a cat. He was treated on Hospital Veterinário Unicesumar Maringá - Paraná, a 1-year-old feline, presenting injury to the thoracic limb after a history of fighting with another animal of the same species. On physical examination, he presented fistula and edema in the right thoracic limb. The patient was anesthetized and debridement of the devitalized areas was performed. As an initial therapy, the lesion was treated as an open wound until granulation tissue was formed for subsequent correction of the defect using a direct pouch bipedicled flap, with temporary fixation of the limb to the chest wall. After two weeks, the limb was unimplanted and the stitches were removed 21 days after flap application. The use of the flap allowed complete wound healing without bruising, necrosis or suture dehiscence. It is concluded that the use of bipedicular flap is applicable to the treatment of traumatic wounds in feline thoracic limb.
\end{abstract}

Keywords: Felines, skin wound, flap.

\section{Introdução}

As lesões de pele têm uma alta casuística na clínica de pequenos animais, essas lesões podem ser causadas por queimaduras, mordeduras, quedas, atropelamentos e agressões. Quando o fechamento primário de uma ferida exerce muita tensão de pele, a cirurgia reconstrutiva se faz necessária (Trindade, 2009; Scheffer et al., 2013).

A indicação da cirurgia reconstrutiva em cães e gatos são as lesões traumáticas, exérese de grandes tumores ou lesões congênitas. Para se obter um bom resultado, é necessário saber em qual fase da cicatrização a ferida se encontra e qual técnica é mais indicada para a região acometida (Amsellem, 2011; Huppes et al., 2013).

Os retalhos bipediculados ou em bolsa são utilizados para reparação de defeitos da pele em extremidades dos membros e sua principal característica é necessitar de três fases para a sua confecção. A primeira fase é o desbridamento e a granulação do tecido receptor, a segunda fase é realizado a criação do retalho e a implantação do membro no leito doador e terceira fase ocorre a liberação do retalho pego a lesão do membro (MacPhail, 2014).

As principais complicações das cirurgias reconstrutivas são as necroses do retalho, seroma, hematoma, infecção, deiscência, auto-trauma, edema (Amsellem, 2011; Huppes et al., 2013).

${ }^{*}$ Recebido em 20 de novembro de 2019 e aceito em 15 de janeiro de 2020.

${ }^{* *}$ Centro de Ensino Superior de Maringá, Departamento de cirurgia veterinária, Maringá, PR, Brasil.

***Universidade Estadual Paulista "Júlio de Mesquita Filho", Departamento de cirurgia veterinária, Jaboticabal, SP, Brasil.

****Pontifícia Universidade Católica do Paraná, Departamento de cirurgia veterinária, Curitiba, PR, Brasil.

*****União das Faculdades dos Grandes Lagos, São Jose Rio Preto, SP.

Autor correspondente. E-mail: crisvaresmvz@gmail.com. 
O objetivo desse trabalho é relatar a confecção de um retalho direto em bolsa bipediculada com fixação apendicular à região torácica para o tratamento de lesões extensas no membro torácico direito de um gato.

\section{Relato do caso}

Felino,1 ano de idade, foi atendido no Hospital veterinário Hospital Veterinário Unicesumar Maringá-Paraná, com histórico do animal ter brigado com outro felino a 4 dias. O membro torácico direito apresentava-se edemaciado. Ao exame físico foi observado presença de fístula em região umeral e grande aumento de volume em todo o membro do animal.

Para uma melhor avaliação e manuseio, o animal foi então anestesiado com citrato de fentanila $3 \mathrm{mcg} / \mathrm{kg}$, cloridrato de cetamina $0,5 \mathrm{mg} / \mathrm{kg}$ e propofol $3 \mathrm{mg} / \mathrm{kg}$, todos em bolus por via intravenosa e manutenção do procedimento de anestesia com isoflurano. Após a sedação o membro foi tricotomizado onde foi visualizado a presença de um abscesso. Para o tratamento foi realizado uma punção com bisturi seguido de higienização da ferida mediante o sistema de frasco de solução fisiológica 0,9\% (500 ml), com equipo, torneira de três vias, seringa de $20 \mathrm{ml}$ e agulha 42x12. Após drenagem e lavagem procedeu-se o desbridamento cirúrgico da pele que se apresentava desvitalizada (Figura 1). Foi então realizado bandagem com kollagenase 0,6 U/g (CRISTÁLIA) e gaze (primeira camada), algodão hidrofílico (segunda camada), atadura e esparadrapo (terceira camada). Foram realizadas trocas diárias dessa bandagem a cada 24 horas e o uso da kollagenase foi sessado no momento em que não se tinha mais tecido desvitalizado e início de formação de matriz extracelular definitiva (tecido de granulação) (5 dias após o desbridamento). Dando continuidade ao tratamento iniciou-se o uso de pomada sulfadiazina de prata $1 \%$.

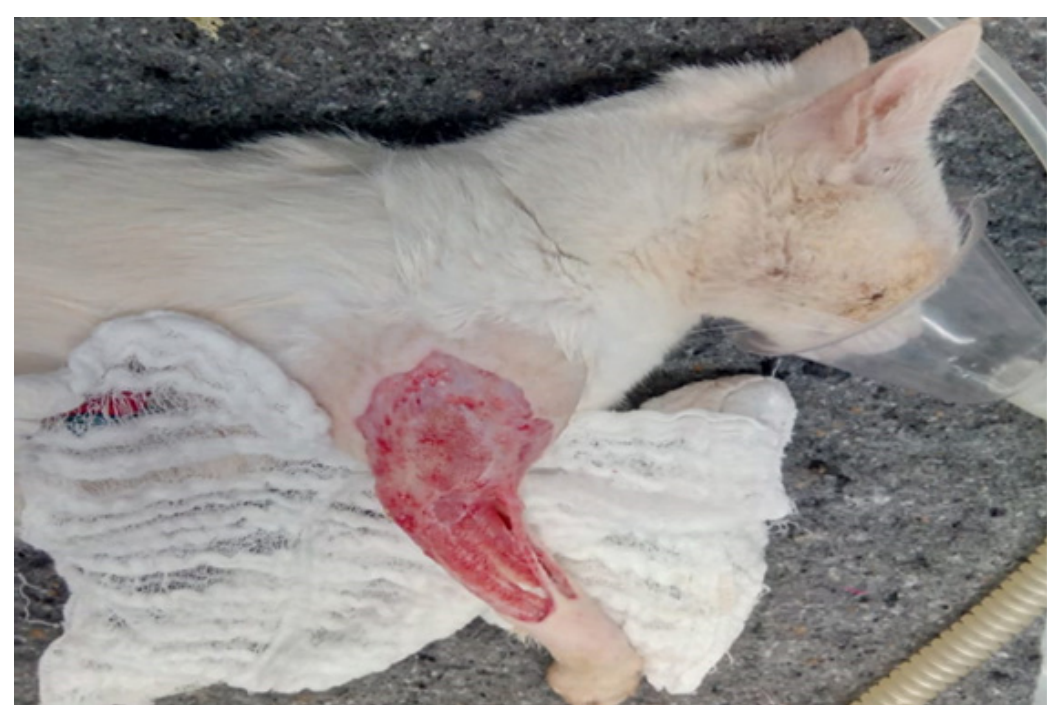

Figura 1: Imagem fotográfica de paciente felino após sedação ambulatorial e debridamento cirúrgico do tecido desvitalizado no membro torácico direito. Arquivo pessoal.

Após 11 dias de manejo clínico da ferida em cicatrização por segunda intenção, sendo (cinco dias de colagenase e seis dias utilizando sulfadiazina de prata 1\%), foi observado a presença de tecido de granulação e então optou-se por tratamento cirúrgico reconstrutivo com o objetivo de acelerar a recuperação e cicatrização mais rápida do membro afetado. A técnica escolhida foi a utilização de retalho bipediculado com fixação temporária o membro a parede torácica. (Figura 2).

Para o procedimento anestésico foi utilizado como medicação pré-anestésica (MPA) cloridrato de metadona $0,3 \mathrm{mg} / \mathrm{kg}$ por via

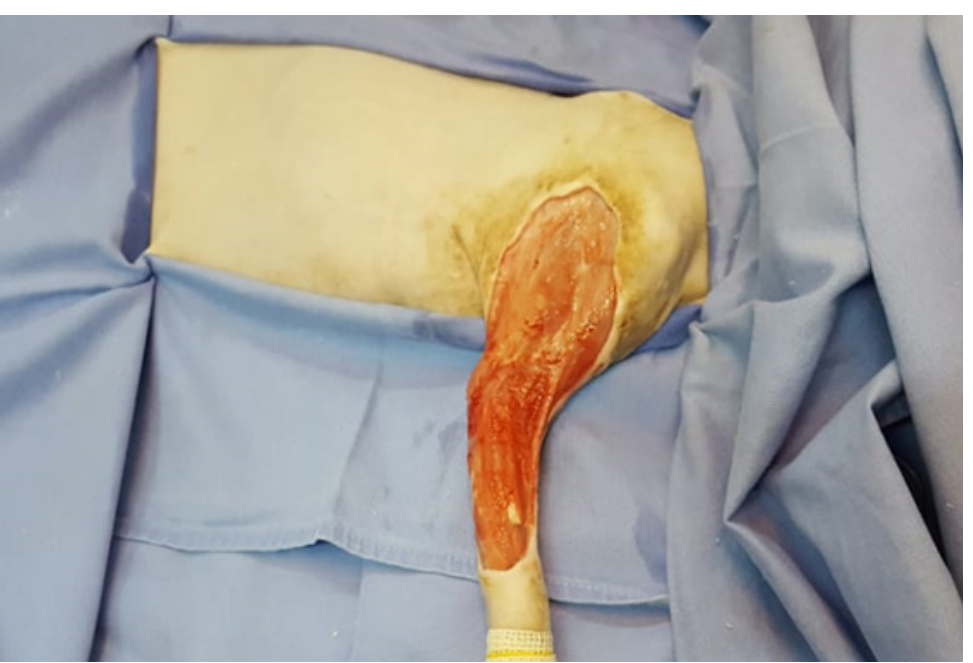

Figura 2: Imagem fotográfica de paciente felino com lesão extensa em membro orácico, após 11 dias de manejo clínico da ferida com presença evidente de tecido de granulação. Arquivo pessoal.

intramuscular. Após 10 minutos foi realizado indução anestésica com fentanil $3 \mathrm{mcg} / \mathrm{kg}$, cetamina $0,5 \mathrm{mg} / \mathrm{kg}$ por via intravenosa e propofol $3 \mathrm{mg} / \mathrm{kg}$, por via intravenosa, seguido de intubação orotraqueal e manutenção com isoflurano.

A antibioticoterapia profilática utilizada foi cefalotina $30 \mathrm{mg} / \mathrm{kg} / \mathrm{IV}$, associada com terapia antiinflamatoria (meloxicam $0,1 \mathrm{mg} / \mathrm{kg} / \mathrm{IM}$ ) e analgesia (fentanil $5 \mathrm{mcg} / \mathrm{kg} / \mathrm{hora} /$ e cetamina $0,6 \mathrm{mg} / \mathrm{kg} / \mathrm{h}$ em infusão intravenosa contínua, durante todo o procedimento).

No primeiro momento cirúrgico, foi feito a exérese das bordas de toda a ferida e o fechamento primário em padrão simples interrompido da ferida na região escapulo umeral. Posteriormente, foi realizado a confecção do retalho bipediculado em dobradiça, onde se aproximou o membro torácico ao tórax para delimitar o local onde seria realizado o retalho em dobradiça, determinando a largura e comprimento do mesmo, (Figura 3). Foram realizadas duas incisões paralelas na pele, cranial e caudal no tórax com a extensão e a largura do ferimento e com tesoura metzenbaum realizado o túnel, por onde o membro será implantado. Seguidamente, o membro torácico foi passado por dentro do túnel (Figura 4) e suturado em padrão simples interrompido com nailon 2-0, (Figura 5).

Para realização da implantação do membro, a pele é elevada e em seguida a extremidade do membro é presa com um cordão de faixa estéril. Este cordão é passado por dentro do túnel e de forma delicada o membro é tracionado até que a extremidade do membro seja exposta. 


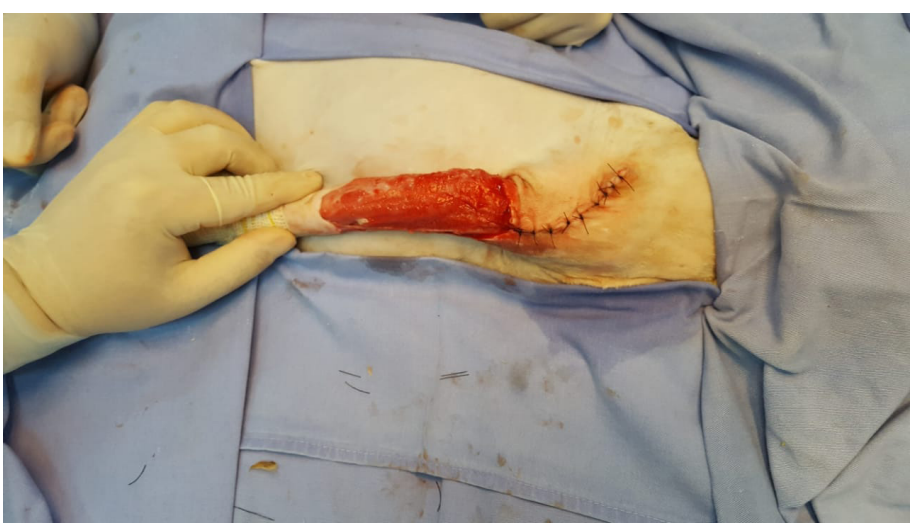

Figura 3: Imagem fotográfica de paciente felino no trans-cirúrgico evidenciando sutura parcial da ferida na região escapulo-umeral e posicionamento do membro para delimitar a largura e comprimento do retalho. Arquivo pessoal.

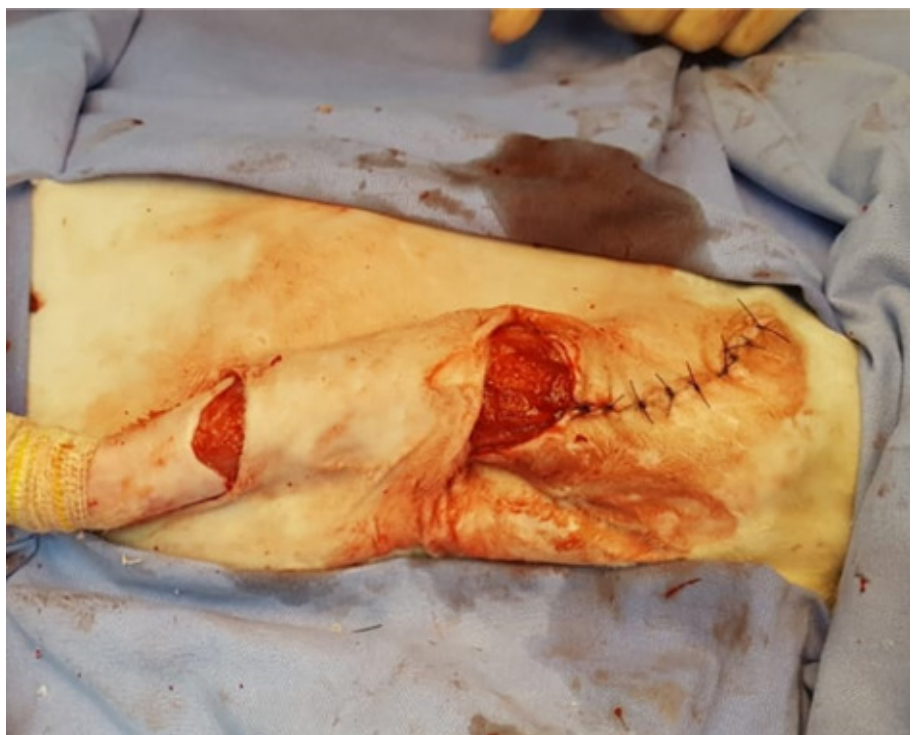

Figura 4: Imagem fotográfica de paciente felino após a liberação do subcutâneo com tesoura de metzenbaum e posicionamento do membro no subcutâneo do leito receptor. Arquivo pessoal.

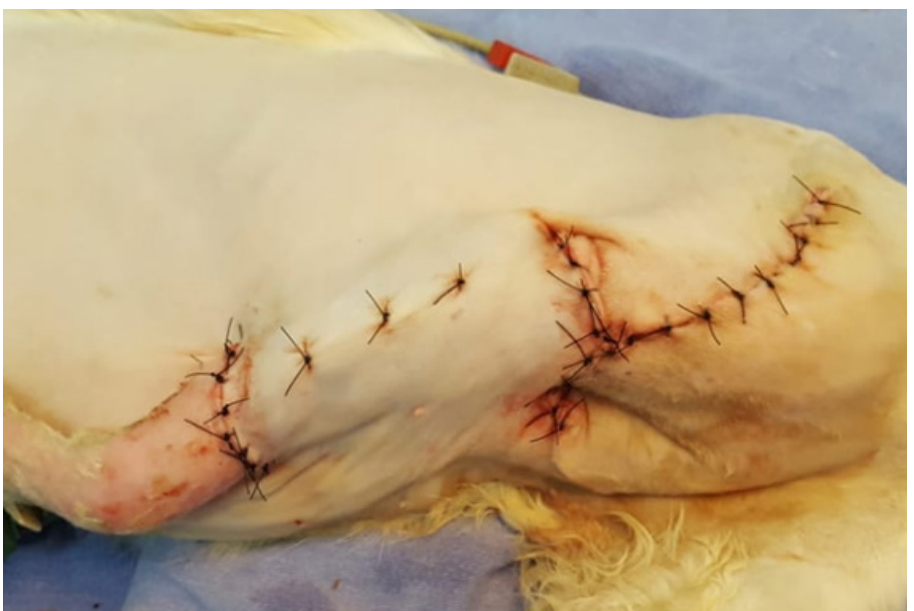

Figura 5: Imagem fotográfica de paciente felino no pós-cirúrgico imediato após implantação do membro torácico no subcutâneo, fixado ao retalho de pele com pontos em padrão simples interrompido, utilizando náilon 2-0. Arquivo pessoal. 
No pós-operatório imediato, foi realizado laserterapia (Laserpulse, IBRAMED ${ }^{\circledR}$ ) de baixa potência $\left(4 \mathrm{~J} \mathrm{~cm}^{2}\right)$ por 3 minutos, e repetida a cada troca de curativos (bandagem). Devido ao animal ser agressivo e a tutora não conseguir realizar a limpeza da ferida em casa, foi solicitado retornar a cada 48 horas para sedação e troca de curativo. Para casa foi prescrito cefalexina $30 \mathrm{mg} / \mathrm{kg} / \mathrm{BID} / \mathrm{VO} / 10$ dias, dipirona $25 \mathrm{mg} / \mathrm{kg} / \mathrm{BID} / \mathrm{VO} / 3$ dias, cloridrato de tramadol $2 \mathrm{mg} / \mathrm{kg} / \mathrm{BID} / \mathrm{VO} / 4$ dias.

Após 15 dias de pós-operatório, o paciente retornou para realizar o segundo procedimento cirúrgico, no qual, o animal foi anestesiado com o mesmo protocolo anestésico já mencionado anteriormente. No transoperatório, o membro foi desimplantado do tórax, para isso se realizou duas incisões, de dois centímetros dorsal e ventral do membro (Figura 6), e em seguida.

As bordas do retalho foram reavivadas, assim como as bordas laterais da ferida do membro, (Figura 7). Em seguida, foi realizada a sutura lateral e medial do retalho ao leito receptor, utilizando náilon 2-0 em padrão simples interrompido. O defeito torácico foi corrigido com redução do espaço morto com sutura em padrão simples interrompido usando poliglecaprone $25,2-0$, e a dermorrafia com padrão simples interrompido utilizando náilon 2-0. No término do procedimento foi realizado Laserterapia $\left(4 \mathrm{~J} / \mathrm{cm}^{2}\right)$ e as sessões no pós-operatório continuaram a cada 48 horas até a retirada dos pontos. Para casa foi prescrito cefalexina $30 \mathrm{mg} / \mathrm{kg} / \mathrm{BID} / 10$ dias, dipirona $25 \mathrm{mg} / \mathrm{kg} / \mathrm{BID} / 3$ dias, cloridrato de tramadol 2 $\mathrm{mg} / \mathrm{kg} / \mathrm{BID} / 4$ dias.

Após 15 dias do procedimento foi realizado a retirada dos pontos e a alta médica foi realizada (Figura 8).

Figura 8. Imagem fotográfica de paciente felino após retirada dos pontos de pele. Repare que na remoção dos pontos foram removidas crostas de necrose da borda da pele, que foram tratadas com sulfadiazina de prata $1 \%$ por 10 dias até a melhora clínica. Arquivo pessoal.

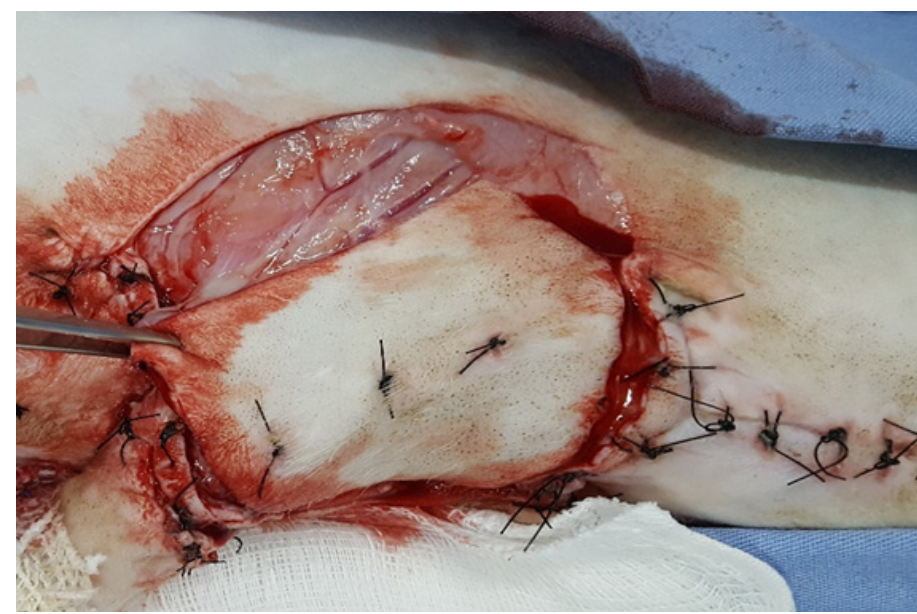

Figura 6: Imagem fotográfica de paciente felino no trans-operatório para o desimplante do membro torácico, após 15 dias da realização do primeiro procedimento cirúrgico. Neste momento foi observado aderência da pele ao leito receptor. Arquivo pessoal.

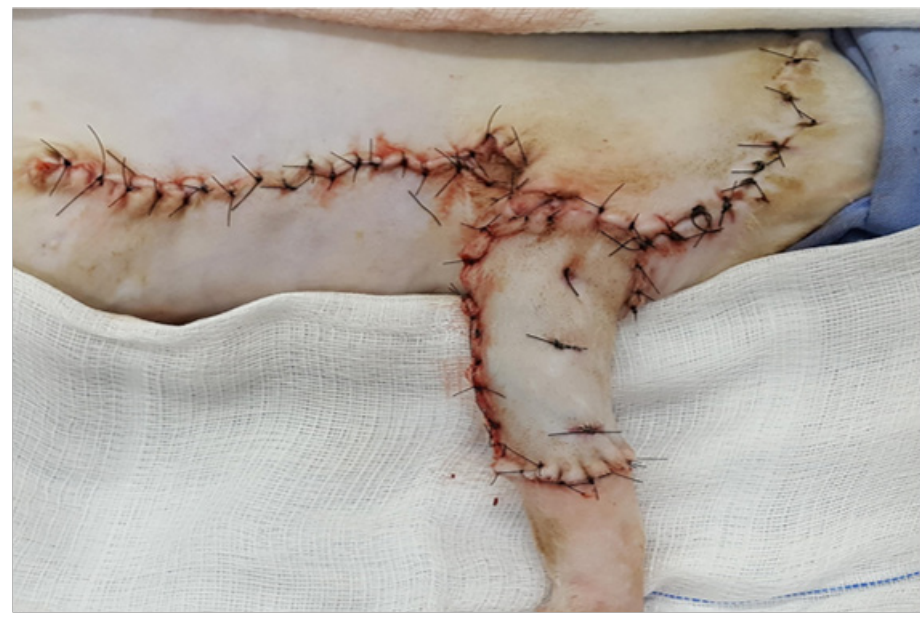

Figura 7: Imagem fotográfica de paciente felino do pós-operatório imediato do desimplante do membro torácico. As bordas lateral e medial do retalho foram suturadas, após o desimplante do membro. Arquivo pessoal.

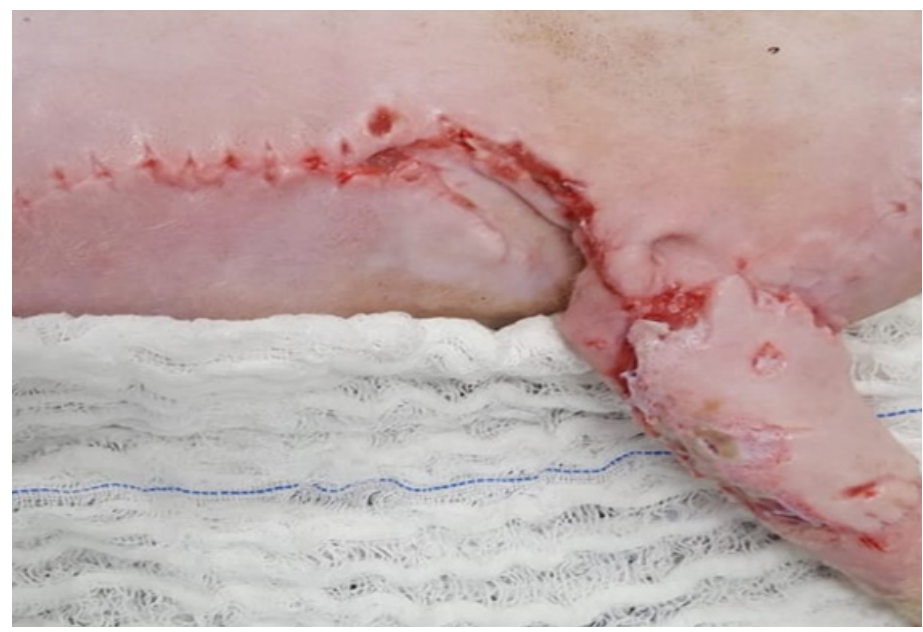

Figura 8: Imagem fotográfica de paciente felino após retirada dos pontos de pele. Repare que na remoção dos pontos foram removidas crostas de necrose da borda da pele, que foram tratadas com sulfadiazina de prata $1 \%$ por 10 dias até a melhora clínica. Arquivo pessoal. 


\section{Discussão e conclusões}

Em feridas contaminadas se faz necessário um tratamento inicial a fim de se desbridar o tecido desvitalizado, diminuir carga contaminante (bacteriana), promover drenagem do local e conseguir um leito vascularizado. Para isso é necessário realizar uma tricotomia ampla, antissepsia, lavagem com soluções salinas ou isotônicas e desbridamento do ferimento (Simas, 2010; Huppes et al., 2013). No presente estudo o tratamento inicial foi realizado com tricotomia, desbridamento cirúrgico, limpeza da ferida com solução fisiológica 0,9\%. Segundo Steed, (2004), a desbridação cirúrgica ocasiona dor, e por tal motivo o paciente deve estar sedado, assim como descrito em nosso relato, o paciente foi submetido a MPA e anestesia para controle da dor. Não necessariamente como descrito neste relato, o paciente deve ser submetido anestesia geral, em alguns casos dependendo da espécie, temperamento do paciente, extensão da ferida e presença de tecido morto as medicações préanestésicas e bloqueios regionais podem ser o suficiente para o procedimento (Steed, 2004).

Como descrito neste relato a lavagem foi realizada de forma abundante com solução fisiológica 0,9\%. Existem inúmeras maneiras de higienização da ferida, sendo descrito a utilização de água corrente, solução fisiológica a $0,9 \%$ ou solução de Ringuer Lactato (Liptak, 1997). Segundo Liptak, (1997), ainda pode associar a estas soluções agentes antissépticos como iodo povidona, clorexidina $0,05 \%$, porém, em nosso paciente a opção foi por não usar antissépticos, visto que a utilização da solução fisiológica $0,9 \%$ de forma abundante já é o suficiente para diminuir a população bacteriana sem atrapalhar a fibroplasia.

Mesmo após a lavagem e o desbridamento cirúrgico, em alguns casos é necessário a utilização de pomada, géis de ação enzimática ou autolítico para o desbridamento. Em nosso paciente foi utilizado a colagenase $0,6 \mathrm{U} / \mathrm{g}$ e gaze seca, caracterizando a associação de ação enzimática com adesão da gaze ao leito como primeira camada da bandagem, posteriormente a segunda camada de algodão hidrofílico (camada de absorção) e terceira camada composta de atadura e esparadrapo (proteção e sustentação), a fim de remover tecido necrosado, absorção de fluidos e diminuir carga bacteriana, assim como proteção da ferida (Pavletic, 2010).

$\mathrm{O}$ intuito deste modelo de curativo foi o desbridamento, pois tecido de granulação não prolifera em feridas contaminadas ou com presença de tecido necrótico. Porém, com este modelo de curativo proporcionamos a estimulação da formação de tecido de granulação, o que poderia favorecer o fechamento da lesão por primeira intenção de forma tardia. Este método permite um maior desbridamento, pois além da ação da colagenase (autólise), a remoção da gaze promove um desbridamento mecânico (Simas, 2010; Huppes et al., 2013; Filho et al., 2014).

Tanto o desbridamento enzimático como o mecânico, foram utilizados até não se existir mais tecido desvitalizado. Segundo Pavletic, (2010) a utilização da gaze seca promove adesão aos tecidos necróticos e com as trocas periódicas ocorre remoção deste tecido por arrancamento. Segundo Steed, (2004), outras opções além da colagenase poderiam ser implementadas, como papaína associada a uréia, que pode promover a destruição da fibrina e colágeno do tecido e desta forma promover a desbridação.
A segunda camada do curativo era formada por algodão hidrofílico, que possui a capacidade de absorver resíduos líquidos, e serve de apoio para a primeira camada. A terceira camada foi formada por atadura e esparadrapo, essa camada tem função de promover apoio, proteção e firmeza para as demais camadas (Simas,2010; Huppes et al., 2013; Filho et al., 2014)

Outra alternativa de tratamento para esta ferida, seria a utilização de antibióticos tópicos, esta modalidade apresenta algumas vantagens como intoxicação bacteriana seletiva, maior eficácia na presença de matéria orgânica e potencialização da medicação sistêmica, como desvantagens o custo é a principal (Liptak, 1997). Após a retirada de todo tecido desvitalizado passou a se usar a pomada sulfadiazina de prata $1 \%$ como antibioticoterapia tópica, essa pomada possui um amplo espectro, baixo risco de toxicidade e alergias (Lopes, 2016). Outra vantagem descrita com a utilização de sulfadíazina de prata é a sua ação contra bactérias gram-positivas e negativas e ação contra fungos (Fahie e Shettko, 2007). No presente estudo, se obteve um resultado satisfatório com a utilização da colagenase e após sulfadiazina de prata $1 \%$ associado a bandagem, observando que em 15 dias a ferida já possuía tecido de granulação e características apropriadas para a realização do procedimento cirúrgico (Fahie e Shettko, 2007)

Feridas em membros torácicos possuem algumas alternativas para a sua correção, esses retalhos irão conseguir fechar a lesão por inteiro ou parcialmente e aumentarão a irrigação sanguínea da região, favorecendo assim o sucesso no tratamento do defeito. Os retalhos que podem ser utilizados no fechamento de defeitos no membro torácico são os retalhos pediculados (retalhos de padrão axial como da artéria torácica dorsal, torácico lateral ou braquial superficial ou subdérmicos utilizando a prega axilar invertida), bipediculados (em bolsa ou dobradiça), retalhos tubulares ou enxertos (MacPhail, 2014; Gusmão, 2019).

Devido ao tamanho do paciente (felino) e do defeito, foi optado pela realização do retalho bipediculado em dobradiça. Segundo Huppes et al., (2013), descreveu esta mesma técnica, porém, em um cão de porte pequeno. Neste relato, a lesão era em 360 graus no membro e envolvia toda a região do antebraço do paciente, o que difere deste relato no felino, que apresentava lesão na região crânio-lateral do antebraço. Outro fator que encorajou a utilização desta técnica foi que os animais apresentavam tamanho e peso semelhante visto que o paciente do presente relato é um felino e o cão um Pinscher, além do resultado positivo no cão.

Independentemente do sucesso da técnica no cão, é importante saber que a cicatrização de feridas por primeira intenção ou segunda intenção é diferente em felinos e caninos. A pele integra de felinos apresenta menor perfusão, feridas tratadas por primeira intenção apresentam menor resistência à ruptura comparado aos cães, este fator nos leva a crer que existe uma menor produção de colágeno nos felinos durante o processo cicatricial. Mesmo sabendo desta diferença na cicatrização por fechamento primário, a opção pela cirurgia foi baseada em estudos, que descrevem uma formação de tecido de granulação retardada, com coloração pálida quando comparação aos cães (Bohling \& Handerson 2006). O tratamento por segunda intenção poderia ser uma opção, porém existe particularidades que nos levaram a optar pela cirurgia. Uma destas particularidades 
é que o subcutâneo é o principal percursor para a formação de tecido de granulação, e devido a formação do abscesso e desbridamento, este tecido foi perdido o que retarda ainda mais o processo cicatricial em felinos, podendo ser necessário meses para o fechamento da ferida, o que poderia inviabilizar o tratamento por segunda intensão (Bohling \& Handerson 2006).

Os retalhos de padrão axial da artéria torácica dorsal, torácica lateral, ambos são os retalhos mais indicados para defeitos em cotovelo, porém, podem ser utilizados no antebraço com resultados reservados, pois devido a extensão do retalho e da sua rotação existe grande possibilidade de necrose. Já o retalho da braquial superficial é um retalho que necessita de uma rotação de 180 graus e recobre regiões como a presente em nosso relato, porém a opção por não utilizar este retalho foi a alta taxa de complicações como necrose de extremidade (Macphail, 2014). Quando utilizamos a prega axilar com base no cotovelo para recobrir defeitos em antebraço, os resultados são promissores, com pega de 80 a $100 \%$ da extensão do retalho, porém, como observado na figura de número 1 , a prega foi envolvida durante o desbridamento e portanto, deixou de ser uma opção para este paciente (Macphail, 2014; Pavletic , 2018).

O enxerto cutâneo seria uma outra opção para o fechamento da lesão, porém, os cuidados pós-operatórios são mais delicados, pois para o enxerto ser bem sucedido, é necessário a revascularização do leito a pele e boa drenagem do líquido tecidual. O leito receptor necessita ter tecido de granulação, ser livre de infecção e não possuir osso, cartilagem, tendões e nervos expostos (MacPhail, 2014). Em nosso paciente, a infecção estava controlada, existia tecido de granulação no leito, fato que permitia a utilização do enxerto, contudo, a preocupação neste caso foram os retornos cirúrgicos, as trocas de bandagem, visto que o enxerto deve ser monitorado a cada 48/72, 96 horas e o proprietário ter afirmado que não seria possível realizar o acompanhamento desta forma, o que fez com que desistíssemos desta técnica.

A utilização de laserterapia na medicina veterinária vem aumentando, autores apontam que a laserterapia de baixa potência pode auxiliar na angiogênese, vasodilatação, aumento de atividade mitocondrial e aumento de adenosinatrifosfato (ATP), síntese protéica, proteção da célula contra danos oxidativos (Andrade et al., 2014). Em nosso paciente a terapia

\section{Referências}

AMSELLEM, P. Complications of reconstructive surgery in companion animals. The Veterinary clinics of North America. Small animal practice, v. 41, n. 5, p. 995-1006. vii, 2011.

ANDRADE, F. D. S. D. S.; CLARK, R. M. D. O.; FERREIRA, M. L. Efeitos da laserterapia de baixa potência na cicatrização de feridas cutâneas. Revista do Colégio Brasileiro de Cirurgiões, 41(2), 129-133. 2014.

BOHLING, S. J; HANDERSON, R.A. Differences in cutaneous wound healing between dog in cats. Veterinary clinics of north american small animal practice, v. 36, n.4, p. 687-692, 2006.

FAHIE, M.A; SHETTKO, D. Evidence-based wound management: a systematic review of therapeutic agentes to enhance granulation and epithelization. Veterinary clinics of north américa small animal pratice. V. 37, n. 3 p. 559-57, 2007. com laser de baixa intensidade se sugere que foi benéfica, visto que diminuiu a presença de edema no pós-operatório imediato fato que minimiza a tensão da sutura nas bordas cutâneas diminuindo as chances de necrose de bordas.

Diferentemente de nosso relato que foi utilizado o Laser em um caso de rotina, com intuito de estimular a cicatrização e pega do retalho, Fortuna et al., (2017), utilizou em seu experimento 40 ratos Wistar, submetidos a cirurgia cutânea e divididos em 2 grupos, controle e o grupo que recebeu laser como modalidade de tratamento. O laser foi aplicado na frequência de $4 \mathrm{~J} / \mathrm{cm}^{2}$, fato que corrobora com nosso relato, porém o intervalo de aplicações foi diferente, nesta pesquisa de Fortuna et al., (2017), o Laser foi utilizado a cada sete dias. Na avaliação histológica e imunohistoquímica, foi evidenciado que havia maior número de vasos sanguíneos no grupo do laser, porém não apresentou diferença estatística sobre VEGF em ambos os grupos. O laser foi mais efetivo no curso final da cicatrização, principalmente no que diz respeito ao colágeno. Vaghardoost et al., (2018), diferentemente de nosso relato e de Fortuna et al., (2017), selecionou 11 pacientes humanos com ulceras ocasionadas por queimaduras de grau 3. Foi utilizado $2 \mathrm{j} / \mathrm{cm}^{2}$, nos dias $0,3,5$ e 7 e a radiação foi realizada no sítio receptor. Como resultado, foi observado que o laser acelera a cicatrização de feridas. Assim como os trabalhos descritos acima, podemos sugerir que a técnica de Laser a 4 j/ $\mathrm{cm}^{2}$ ajudou na angiogênese e colagenase. A colagenase é um percursor pouco produzido durante o processo cicatricial de felinos, porém com a utilização do Laser de baixa frequência pode ser estimulada, fato que pode ser atribuído em nosso relato, pois após 15 dias do procedimento o retalho se apresentava aderido no leito receptor e nas bordas da ferida com pequenas áreas de desvitalização, fato que não interferiu na alta médica.

\section{Conclusões}

Cuidados do tutor com animal e retornos periódicos ao hospital veterinário, um bom manejo da ferida (desbridamento e estímulo de formação de tecido de granulação), escolha do momento ideal para operar, utilização de técnica apropriada e manejo do retalho com proteção (bandagem), higienização (limpeza com solução fisiológica), Laser $4 \mathrm{j} / \mathrm{cm}^{2}$, fizeram com que o procedimento clínico e cirúrgico fosse eficaz no tratamento da lesão do antebraço do felino.

FILHO, N. P. R.; MENDES, D. E.; SOUZA, M. S. B.; ARIAS, M. V. B. Uso de coberturas no tratamento de feridas de cães e gatos. Revista Científica de Medicina Veterinária - Pequenos Animais e Animais de Estimação. v.12 p.424-435, 2014

FORTUNA, T.; GONZALEZ, A. C.; SÁ, M. F.; ANDRADE, Z. D. A.; REIS, S. R.; MEDRADO, A. R. Effect of $670 \mathrm{~nm}$ laser photobiomodulation on vascular density and fibroplasia in late stages of tissue repair. International wound journal, 15(2), 274282, 2018.

GUSMÃO, B.D.S.; VERDELONE, C. X.O.; DE NARDI, A. B.; REIS FILHO, N.P. Técnicas de reconstrução para defeitos cutâneos em região de cotovelo. Investigação, 18(1). 2019.

HUPPES, R. R.; ZANELLA, J. C.; NARDI, A. B. D.; CASTRO, J. L. C.; USCATEGUI, R. A. R.; PAZZINI, J. M.; SOUZA, F.W.; SILVA, J.A.R; AMORIM, R. L. Flape bipediculado no tratamento de lesão cutânea em membro torácico de cão-relato de caso. $J$. bras. cir. vet, 2(2), 98-101. 2013. 
LIPTAK, J. M. Na overview of the topical management of wounds. Australian Veterinary Journal, v. 75, n. 6, p. 408-413, 1997.

LOPES, M.A.I. Abordagem e maneio médico-cirúrgico de feridas abertas em cães e gatos: caracterização etiológica e estudo de padrões traumáticos. 2016. Tese (Doutorado). Faculdade de Medicina Veterinária. Universidade de Lisboa. 2016.

MACPHAIL, C.M. Cirurgia do sistema tegumentar. In: FOSSUM, Theresa Welch (Ed.). Cirurgia de pequenos animais. Rio de Janeiro, Elsiever, p. 190-278. 2014.

VAGHARDOOST, R.; MOMENI, M.; KAZEMIKHOO, N.; MOKMELI, S.; DAHMARDEHEI, M.; ANSARI, F.; NILFOROUSHZADEH, M. A.; JOO, P. S.; ABADI, S. M.; GHARAGHESHLAGH, S. N.; SASSANI, S. Effect of low-level laser therapy on the healing process of donor site in patients with grade 3 burn ulcer after skin graft surgery (a randomized clinical trial). Lasers in Medical Science, 33(3), 603-607, 2018. doi:10.1007/s10103-017-2430-4

PAVLETIC, M. M. Atlas of small animal wound management and recosntructive surgery. 3 ed. lowa: Wiley-Blackwell, 2010.
PAVLETIC MM. Axial Pattern Skin Flaps. In: Pavletic MM. Atlas of Small Animal Wound Management and Reconstructive Surgery. 4. ed. lowa: Wiley-Blackwell, pp. 418-460, 2018

SCHEFFER, J. P.; ATALLAH, F. A.; GOMES, C.; ESTUPÑAN, O. F. T.; SILVA, S. J. Q., SILVA, T. I. R.; VALE, D.F.; DE ABREU OLIVEIRA, A. L. Cirurgia reconstrutiva no tratamento de feridas traumáticas em pequenos animais. Brazilian Journal of Veterinary Medicine, 35(Supl. 1), 70-78. 2013.

SILVEIRA, P.C.L.; SILVA, L.A.; TUON, T.; FREITAS, T.P.; STRECK, E.L.; PINHO, R.A. Efeitos da laserterapia de baixa potência na resposta oxidativa epidérmica induzida pela cicatrização de feridas. Brazilian Journal of Physical Therapy/ Revista Brasileira de Fisioterapia, 13(4). 2009.

SIMAS, S.M. O tratamento de feridas cutâneas em cães e gatos. 2010.

STEED, D. L. Debridement. The american Journal of Surgery. V. 187, n. 5, p. 71-74, 2004.

TRINDADE, J.T. Uso da cirurgia reconstrutiva no tratamento de feridas cutâneas abertas em cães e gatos. 2009. 